\title{
Revolutionizing Education: Youth Participatory Action Research in Motion
}

Julio Cammarota \& Michelle Fine (eds), Routledge, New York \& London, 2008, 256 pages

\author{
Katie Richards-Schuster \\ University of Michigan
}

Gateways: International Journal of Community Research and Engagement Vol 3 (2010): 187-189 CUTSePress and the author

ISSN 1836-3393
In which ways is research revolutionary and transformative? How can research be a systematic approach to social change and critical epistemology? How do youth gain the skills to engage in critical research and what are the implications of their efforts for creating change in communities, institutions, education systems, academic settings, and society? These are the provocative questions that Cammarota and Fine raise in their important book Revolutionizing education: Youth participatory action research in motion.

Cammarota and Fine describe youth participatory action research (YPAR) as providing 'young people with opportunities to study social problems affecting their lives and determine actions to rectify these problems'. Their definition is not simply one of youth involvement in research but rather incorporates a deeper notion of the power that can be generated when critical inquiry is linked to creating social change and challenging systems of oppression. They discuss YPAR both for its radical and revolutionary challenge to 'traditional research' practices but also for its active focus on research as a vehicle for increasing critical consciousness, developing knowledge for 'resistance and transformation', and for creating social change.

The book contains a series of case study chapters that examine how YPAR transforms young people and the social contexts in which they live as well as the learnings and implications yielded from this research. These chapters, co-written by youth and adult researchers, focus on five case examples of communities across three US states (Arizona, California and New York). The book also includes four chapters that examine the theory and practice of YPAR as an approach that challenges traditional notions of research and current approaches to education pedagogy.

Each of the five case chapters provides rich detail and focus on the research process, including the design and implementation, and implications of the research for social change. For example, Cahill et al.'s chapter explores their participatory research project 
examining everyday living in the Lower East Side of New York City. In this chapter, the authors detail the development of the research process and the critical insights gained from that process for understanding their own lives and those of their community. Romero et al.'s chapter discusses the Social Justice Education Project (SJEP) in Tucson which engages young people in the public schools in participatory research on social and structural issues impacting Latina/o students. It includes short writings by students about their experiences in SJEP and focuses on the success, struggles and lessons learned over this five-year project and the pedagogical theory underlying the project. Morell et al.'s chapter describes the work of the Institute for Democracy, Education and Access (IDEA) in Los Angeles and the participation of young people in a summer seminar in which they used critical research as a tool for youth engagement and for exploring social topics such as student rights, the experience of youth of color in public schools and civic education in schools.

A unique aspect of this book is that each of the chapters is followed by a commentary from a senior scholar. The scholars Sandy Grande, Maxine Greene, Pauline Lipman, Luis Moll and John Rodgers - discuss the chapter, the educational pedagogy and the research project's potential for transformation. The commentaries challenge the reader to consider larger questions raised by each of the chapters, including questions about democratic practice, political sovereignty, authentic learning, critical social praxis and education reform.

The concluding chapters of the book focus on the role of participatory action research in reforming education systems and reforming and redefining research. Cannella's chapter challenges education systems to value the potential of participatory action research as an effective and valuable educational approach in contrast to the current approaches prescribed through federal US education policies like No Child Left Behind.

A concluding chapter by Fine looks at participatory action research through the university lens. Her chapter is a hypothetical letter to a tenure committee in support of an assistant professor whose scholarship is rooted in participatory action research pedagogy. Fine challenges traditional notions of research and argues for the merit and value of participatory action research not as an alternative to traditional research, but rather as a more essential form of research.

Revolutionizing education is deeply reflective and retrospective scholarship on critical questions about YPAR. Throughout the various chapters, the editors push the reader to examine the ways in which YPAR projects encourage 'new meanings of education' and call for an examination of the way education settings can be transformed through 'the acquisition of intellectual resources through which students initiate revolutionary projects to transform themselves and the worlds they inhabit'. In doing so, the authors lay the foundation for examining YPAR not as a method but 
rather as an epistemological and pedagogical approach that fundamentally challenges the way society views knowledge development, research and education. Fine concludes the book stating that she hopes that one day 'YPAR comes to be recognized as a gift of critical pedagogy, deliberative public scholarship, and a delicious space for imaging multi-generational possibilities for a very different tomorrow'.

Revolutionizing education is an important contribution to the field of youth participatory action research. It creates the 'delicious space' through which readers can begin to imagine these possibilities and critically examine their own understanding of their work and its potential for revolutionising and transforming individuals and society. 